\title{
Opportunities and Limitations of Construction Kits in Culturally Responsive Computing Contexts: Lessons from ScratchJr and Family Creative Learning
}

\author{
Ricarose Roque \\ University of Colorado Boulder \\ USA \\ ricarose@colorado.edu \\ Kathryn McConnell \\ University of Colorado Boulder \\ USA \\ Kathryn.Mcconnell@colorado.edu
}

\author{
Mariana Tamashiro \\ Aarhus University \\ Denmark \\ mariana@cc.au.dk \\ Julisa Granados \\ University of Colorado Boulder \\ USA \\ Julisa.Granados@colorado.edu
}

\begin{abstract}
In this paper, we investigate the opportunities and limitations that emerge when we engage youth and their families in creating and sharing stories with a computational construction kit, specifically the ScratchJr programming environment. We examine the participation of children and their families in the Family Creative Learning program, a culturally responsive computing context that engages families to create and share stories with computing. Our findings highlight the ways that families discovered new possibilities for their storytelling using the computational construction kit, but they also experienced challenges in representing their stories and themselves. We discuss the opportunities in storytelling with construction kits and possible limitations when designing to support expression, especially among groups historically marginalized from computing spaces.
\end{abstract}

\section{CCS CONCEPTS}

- Human-centered computing $\rightarrow$ Empirical studies in $\mathrm{HCI}$.

\section{KEYWORDS}

computational construction kits, storytelling, family learning, culturally responsive computing

\section{ACM Reference Format:}

Ricarose Roque, Mariana Tamashiro, Kathryn McConnell, and Julisa Granados. 2021. Opportunities and Limitations of Construction Kits in Culturally Responsive Computing Contexts: Lessons from ScratchJr and Family Creative Learning. In Interaction Design and Children (IDC '21), June 24-30, 2021, Athens, Greece. ACM, New York, NY, USA, 11 pages. https: //doi.org/10.1145/3459990.3460728

This work is licensed under a Creative Commons

Attribution-NonCommercial-NoDerivs International 4.0 License.

IDC '21, fune 24-30, 2021, Athens, Greece

(c) 2021 Copyright held by the owner/author(s).

ACM ISBN 978-1-4503-8452-0/21/06.

https://doi.org/10.1145/3459990.3460728

\section{INTRODUCTION}

Computational "construction kits" which include programming environments designed for children have played an important role in enabling children to create and express themselves in new ways with technology [31]. For example, children can create their own digital games, interactive musical instruments, or collaborate with groups of kids around the world in an online community [7, 8, 29, 37]. Programming environments such as ScratchJr have been designed for children as young as 5 years old to create stories, animations, and games with code [11,45]. As young children engage with these technologies, they are developing new ways to express themselves. At the same time, they can engage in computational thinking ideas while developing perspectives on themselves and their digital world [38].

However, there can be limitations to how expressive these tools can be. These limitations can have implications for what and how people are able to create and express with these tools - and it can have impacts on who creates. As computing education gets widespread recognition and resources, many scholars and educators have highlighted the importance of paying attention to issues of equity that extend beyond access [22, 35, 41]. Culturally Responsive Computing (CRC) approaches position children as creators who can leverage technology to learn not just about computing, but also to learn about their intersectional identities [36]. These tenets also include reimagining "who creates, for whom, to what ends rather than who endures socially and culturally irrelevant curriculum." [36]

In this paper, we apply these critical questions in the design of computational construction kits, focusing particularly on the ScratchJr programming environment, a popular tool designed for children ages 5-7 years old. In 2019, ScratchJr was downloaded around 22 million times since it was first launched in 2014 [12]. We examine the opportunities as well as the limitations of computational construction kits in CRC contexts, focusing on youth and families who have been historically marginalized from computing spaces. We situate their making within a storytelling activity. Stories are a powerful medium in which families engage in remembering, share knowledge and values, and socialize their children [18]. In learning environments that leverage these computational construction kits, storytelling has often been the means in which 
computing is integrated in culturally meaningful ways that invites learners' "funds of knowledge," or cultural practices, backgrounds, and resources $[23,28,40]$. We use the context of a technology program called Family Creative Learning (FCL) to examine possibilities as well as the limitations that emerge with ScratchJr.

We draw from Ingold [16] who argued that "making is a practice of weaving, in which practitioners bind their own pathways or lines of becoming into the texture of material flows comprising the lifeworld." We recognize that the possibilities of making with these computational construction kits are a generative and improvisational interaction between the makers, the materials, and the activity. To capture the complexity in the process of representing their stories, we used ethnographic methods, and our data collection included field notes, screen recordings, projects, and interviews with family members. Our study was guided by the following questions: (1) What opportunities do families encounter when they represent their stories with a computational construction kit? (2) What challenges did families face and how did they respond to these challenges?

Our findings include vignettes of how these opportunities and limitations impacted families' abilities to express and represent their stories. We found instances of families leveraging the affordances of ScratchJr such as whimsical images or computational loops to express their stories in new ways. All families experienced challenges and limitations such as how to translate imagined scenes or events into the tool, but these were also instances where families' "funds of knowledge" shined as they worked around these challenges. Some limitations and challenges also underscored research by scholars who have critically examined program and technology design in HCI, Learning Sciences, and other allied fields of work: embedded biases in creative technologies that can impact what and how can be expressed and who and what can be made visible in the tool $[1,20,21]$. We conclude with a discussion on the opportunities and limitations and how to leverage the possibilities as well as mitigating the more constraining and possibly harmful challenges.

\section{BACKGROUND}

\subsection{Computational construction kits as materials for children}

In this paper, we focus on computational "construction kits" for children. Resnick and Silverman defined "construction kits" as "systems that engage kids in designing and creating things, sometimes on the screen, sometimes in the physical world, sometimes both" [31] We highlight computational construction kits to focus on kits that incorporate computer programming or code into how and what people can create and build. Creating with code can offer people new possibilities to express themselves with technology as they create interactive media such as games, stories, and animations. Computational construction kits could include programming environments like Scratch, physical computing kits like the Lilypad Arduino, or robotics kits such as the Hummingbird kit [6, 26, 29]. Many of these kits have built on the ideas of the constructionist framework, which emphasizes that people learn most effectively when they are building things they care about in a socially supportive environment $[27,29]$. As they build projects, they build ideas. Creating with code is an especially concrete way to engage in computational thinking concepts and perspectives while engaging in design practices such as experimentation, remixing, and iterating on projects $[5,11]$.

Seymour Papert positioned the computer as a "material" that could be manipulated like paint, clay, and paper and called on designers to shift away from "rigid" notions of computers [13]. Resnick and Silverman echo this creative fluidity with computers in their design principles for construction kits for kids [31]. One principle emphasized supporting "many paths, many styles" to encourage multiple ways of doing and thinking. Similarly, Resnick and Silverman encouraged designing for "low floors and wide walls" making it easy to get started and explore many possibilities.

In this paper, we focus on the ScratchJr programming environment, which was designed with these principles in mind "to be inviting and accessible to young children with a variety of styles of thinking and creating" [11]. ScratchJr was designed for children ages 5-7 years old and is especially suited for telling stories. We discuss the features of ScratchJr in more depth in our Methods section. In this paper, we explore both the opportunities and the limitations of ScratchJr as families represent their stories. We highlight the new possibilities that emerged in their storytelling, but also highlight the tensions and challenges that emerged when we asked them to create with ScratchJr in a culturally responsive activity that leveraged their family stories. These possibilities and tensions have implications for the design of computational construction kits.

\subsection{Culturally responsive computing}

Culturally responsive computing has been a valuable approach in engaging more diverse groups in computing and addressing the underrepresentation of people of color and other nondominant groups, who have been historically marginalized from computing opportunities because of race, ethnicity, class, or immigration status $[15,36]$. For example, some tools have been created to situate computation within specific cultural practices such as Native American beadwork or fractal models of traditional African arts and architecture [10]. In this article, we build on other forms of culturally responsive approaches in computing, which aim for more openended design experiences rather than engaging people in tools that situate computing within specific practices. Kafai et al [17] argued that open-ended design experiences can cultivate learner agency while also developing learners' identity within their cultural context and place. We pull on framings of culture that position it as "dynamic, interactional, and emergent" [14] rather than static and unchanging.

For a specific framing of culturally responsive computing, we build on Scott, Sheridan, and Clark framework, which described five tenets in culturally responsive computing [36]:

(1) All students are capable of digital innovation.

(2) The learning context supports transformational use of technology.

(3) Learning about one's self along various intersecting sociocultural lines allows for technical innovation.

(4) Technology should be a vehicle by which students reflect and demonstrate understanding of their intersectional identities. 
(5) Barometers for technological success should consider who creates, for whom, and to what ends rather than who endures a socially and culturally irrelevant curriculum.

In many ways the design of construction kits connects with these tenets, such as tenets (1) and (2) which aim to position youth as creators rather than consumers of technologies. The principles of "wide walls" and "many paths, many styles" connect to tenet (4) which can open opportunities for youth to use technology to explore, recognize, and express their intersectional identities. In this paper, we explore the ways that construction kits connect or fail to support these tenets, especially tenet (5) which assesses meaningful experiences based on "who creates, for whom, and to what ends."

\subsection{Storytelling and construction kits}

Storytelling has been a valuable context for creating with code in culturally responsive and sustaining ways [20, 21, 40]. Engaging in the practice of storytelling can also be a means in which family members can express knowledge, values, and lessons they want to share across generations. In their TechTales program, Tzou and colleagues engaged indigenous families in storywork using robotics and craft materials to build dynamic dioramas based on family stories [40]. Families were able to leverage these tools and materials for their collaborative family making and engage in cultural presence and resurgence [40]. These efforts highlight the promising ways in which computational construction kits combined with meaningful cultural practices like storytelling can spark interest, engage in new expressions, and cultivate positive identities in the context of computing.

In addition to research that highlights the transformative possibilities with computing and storytelling, there has been scholarship that highlights the limitations and challenges of engaging nondominant groups with computational construction kits and other creative technologies [1, 20, 21]. In their microsociology of Minecraft, Ames and Burrell studied an in-person workshop that engaged youth from nondominant groups in an online Minecraft camp, which also hosted youth from other locations [1]. While the workshop and the online Minecraft camp supported access to Minecraft and technological skill development, Ames and Burrell found that features in Minecraft and in the online camp invisibilized and marginalized participants' interests, language, race, and gender [1]. In two studies of programming environments RPGMaker and ARIS, Litts and colleagues examined the ways that these tools both supported and hindered indigenous youth from authentically engaging in storytelling as a cultural practice. They highlighted the assumptions embedded in the design of the tools which prioritized some forms of storytelling over others and hindered students' abilities to fully express their identities and stories [20,21].

In this paper, we aim to build on and extend the scholarship of these prior studies. Using ScratchJr in the context of families representing their stories in FCL, we examine both the opportunities and the limitations that emerged. Examining both opportunities and limitations enable us to also highlight how they interacted and impacted what and how families were able to represent their stories. We pull on framings of material interaction as a generative and improvisational process between the material and the maker [16]. We understand that the possibilities and limitations of tools like ScratchJr emerge as people create with them and, as Tzou et al. emphasized, "in relation to our experiences, histories, and futures with them. [40]"

"In this way, what is defined as "material" and how relations to particular materialities are narrated and enacted are shaped by knowledge systems and shape culturally and sociopolitically consequential constructions, orientations to, and practices with materiality [2]. This is why stories matter-and it matters what materialities help narrate these stories, for whom, and for what purposes." [40]

While families ran into challenges, these challenges became opportunities for families to extend their stories and their learning. Similarly, we complicate what seemed like design affordances that could promote expression but instead seemed to hinder families abilities to represent their identities and stories.

\section{METHODS}

We drew upon ethnographic methods to capture the complexity of families' interactions with a computational construction kit as well as what possibilities and tensions emerged over time. We collected multiple forms of observational, process, and reflective data in the form of field notes, photo documentation, project artifacts, screen recordings, and interviews with participants. Specifically our study examines a workshop series that engaged young people and their families to represent their stories with ScratchJr in the Mountain West region of the United States in the fall of 2018.

\subsection{Author Positionalities}

All authors participated as participant observers and facilitators in these workshops. They played various roles that included supporting families in creating projects, providing language support for parents, and introducing ScratchJr. Three of the authors were able to engage with families in Spanish. One of the authors is a university professor, directs the FCL project, has a background in computer science, and identifies as Filipina-American and an immigrant. Another author was a graduate research assistant and has a background in design, and identifies as Brazilian. The two other authors were undergraduate research assistants and had backgrounds in psychology and bilingual education and political science. One of them identifies as white and the other as a first generation MexicanAmerican. All authors wrote field notes after each workshop and participated in the data collection and analysis.

\subsection{Family Creative Learning Workshops}

We conducted a series of four workshops with children (ages 5 and up) and their family members as part of the Family Creative Learning (FCL) project [32]. The series culminated in a project showcase. During the workshops, the families and facilitators ate dinner together, made projects using creative technologies, and shared their projects with other families. These workshops were part of a larger research program studying how families create and learn together with computing [32] where multiple workshop programs are being conducted in the Mountain West region of the United States. The design of the FCL workshops has been informed by community-based partners, feedback from families, and 
influenced by constructionist and sociocultural perspectives on learning [19, 25, 27]. These two perspectives resonate with the CRC goals of supporting transformative uses of technology in culturally responsive ways.

\subsection{Workshop Structure}

Each workshop was divided into four parts: Eat, Meet, Make, and Share. In Eat, workshops began with a meal from a local restaurant, where all families and facilitators ate together. In Meet, facilitators met separately with parents and children to talk about their experiences in the workshops. In Make, parents and children engaged in design activities with ScratchJr. In Share, families talked about their projects to other families and received feedback and questions. Each family had an iPad tablet with ScratchJr installed. Some families who had more than two people were offered the option of an additional iPad to better manage collaborative dynamics between family members.

The activities in the workshops were organized as follows:

- Workshop 1: During Meet, facilitators introduced parents separately to ScratchJr. During Make, parents then introduced their kids to ScratchJr and explored together.

- Workshop 2: Facilitators prompted families to create a story based on a favorite family story, such as a family trip, or future trip or event they would like to do together. Parents and kids first created and shared their story on a paper-based storyboard then represented their story in ScratchJr.

- Workshop 3: Families continued to work on their stories in ScratchJr with the support of facilitators.

- Workshop 4: Families shared their stories with other families during a community showcase where other families, staff, and local leaders from the community were invited.

\subsection{Storytelling with ScratchJr}

In these workshops, we engaged families using the ScratchJr programming environment, a visual, block-based programming environment that was designed for kids ages 5-7 years old [11]. We selected this programming environment to be able to engage the young children (grades K-2) while still being able to support their older siblings.

We consider ScratchJr a computational "construction kit" using Resnick and Silverman's definition of construction kits as "systems that engage kids in designing and creating things." [31]. In the case of ScratchJr, kids can create and design interactive stories and animations. ScratchJr has both computational and digital features in its programming environment. The computational features include the block-based programming, where kids can program "characters" using various categories of blocks that represent different programming commands such as movement, control flow, and events. Kids can drag and drop blocks and connect them from left to right to represent a sequence of commands. Each character has its own programs, and collections of characters are encapsulated in different "pages" that can represent scenes in a story (Figure 1a).

The digital tools include the characters, backgrounds, and features that allow kids to customize or create additional assets. When someone opens ScratchJr for the first time, they see an orange cat in the middle of a blank stage. ScratchJr includes a built-in library of backgrounds and characters and includes one built-in audio clip that makes a "pop" sound. The library of characters includes animals, people, vehicles, plant life, and objects (Figure 1b). The library of backgrounds include classrooms, parks, urban areas, and space scenes. There is a paint editor where users can modify any of the built-in images or draw their own images to use as characters and backgrounds. There are specially designed characters with blank faces that allow users to take a picture of their face and embed it into the character.

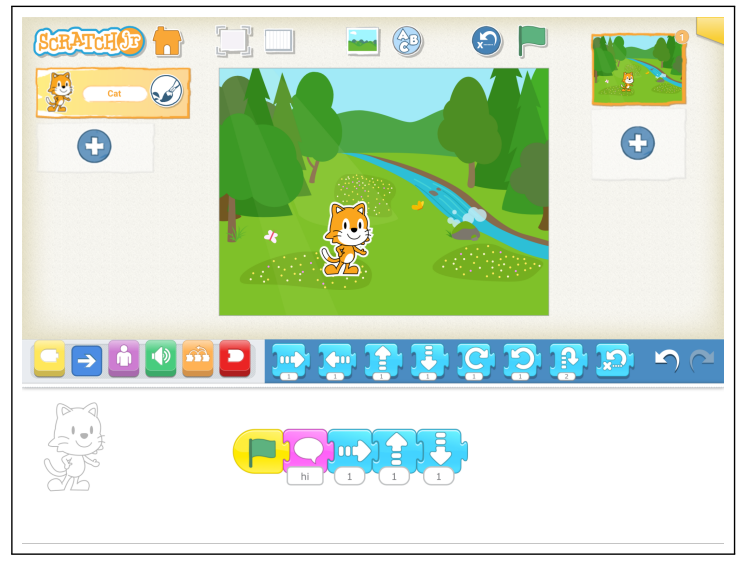

(a) ScratchJr project

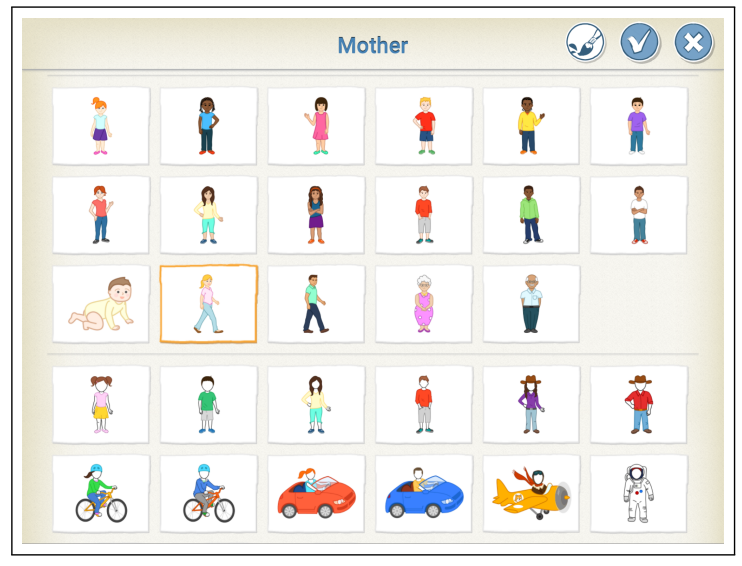

(b) Screenshot of provided assets in ScratchJr.

Figure 1: ScratchJr programming environment

\subsection{Facilitators}

Facilitators for the workshops included four undergraduate students, three graduate students, and one professor. During the workshops, facilitators were also participant observers. All the facilitators but one were novices with ScratchJr. Three facilitators, including the one who was familiar with ScratchJr, had prior experience with some programming environments. Facilitators play important roles in welcoming and supporting families, which include helping families get started with the technologies, encouraging 
families to tinker and experiment, surfacing their interests, and building relationships with family members [33, 34]. Prior to the workshops, facilitators met as a team to become familiar with the tools, activities, and facilitation. During the workshops, facilitators supported the workshop implementation and helped families with their projects. Immediately after a workshop session, facilitators discussed what went well, what questions they had, or things that could be improved or challenging interactions they witnessed.

\subsection{Participants}

The FCL workshops were conducted at an elementary school in the Mountain West region of the United States. The four workshops were held once a week for two hours in the evening to enable parents to participate. We worked with a teacher at the school to recruit 1st and 2nd grade students from the "English Language Learners" program, which consisted of students whose families recently immigrated to the United States, primarily from Mexico. We recruited a total of 9 families, or 25 participants: 14 children (ages 5 to 10 years old; 7 male, 7 female) and 11 adult caretakers (4 male, 7 female). All participants self-identified as Hispanic/Latino. All children attended the elementary school and qualified for free and reduced lunch. Six families participated through the end of the series. Other families had to drop out for various reasons that included family emergencies and work conflicts. We use pseudonyms to refer to participants.

\subsection{Data Collection}

To capture families' complex experiences creating and sharing stories in the workshops, we collected various forms of data that included ethnographic field notes written by facilitators, photo documentation, and screen recordings of families' tablets during Make and Share, when the families were using the tablets to create and share stories with ScratchJr. Ethnographic field notes written by facilitators captured the interactions between families, facilitators, the materials, and the space. Photo documentation included pictures of families' storyboards and their spatial and physical arrangements during Make. Screen recordings enabled us to examine the more granular interactions between family members and the ScratchJr environment. Screen recordings captured audio from the input microphone as well as audio generated from ScratchJr. In addition, to understand families' experiences from their perspective, we conducted 30-90 minute post-workshop interviews with each family member. We asked questions such as "What inspired you to create this story?" and "What was it like using ScratchJr?" Of the nine families who attended, five families participated in the interviews, representing 17 individuals. Interviews were audio recorded and transcribed for analysis.

\subsection{Analysis}

We focused on screen recordings of families' story making to observe how and what stories were created, facilitator field notes to provide context in what was happening in the workshops, and family interviews to examine participants' perspectives on their stories and their process for making them. We also used the photo documentation of families' storyboards. The screen recordings across the four workshops resulted in 36 screen recordings with approximately 19 hours of recordings. Screen recordings only included the activities when families were creating and sharing their projects with ScratchJr during Make and Share. There were a total of 25 fieldnotes and 17 interviews with family members (which represented five families).

We leveraged sociocultural perspectives on learning to examine families' experiences $[19,25]$. Sociocultural perspectives center learning as participation in valued social and cultural practices (as opposed to cognitive perspectives that center individual mental processes). In other words, learning is a relational and cultural process. We did an iterative thematic analysis focusing on family interactions around their story development (e.g. how families worked together, how families told stories) as well as moments where storytelling intersected with features of ScratchJr, such as characters, programming blocks, and other media. To examine families' engagement with the computational features of ScratchJr, we used the Computational Thinking framework from Brennan and Resnick to identify computational concepts (e.g. sequence, parallelism, data) and computational practices (e.g. experimenting and iterating, testing and debugging, abstraction and modularization)[5]. Three research assistants transcribed the screen recordings for three families for the first two workshops. These transcriptions included dialog, descriptions of actions on the screen, screenshots, and timestamps. These transcriptions were reviewed together in a team meeting and used to develop an initial set of categories that described the storytelling process, family interactions, and computational thinking concepts and practices that families engaged in. We tested and refined each code through peer examination until we reached an agreement within the research team. With the codebook defined, we coded the rest of the screen recordings, field notes, and interviews. We used our process of coding and discussion to identify moments where families encountered opportunities or challenges, using the CRC framework from [36] to guide our discussions. For opportunities, we identified moments where families were able to use the features of ScratchJr to express themselves and their family stories. For challenges and limitations, we identified moments where families experienced friction in their process such as having to make compromises or being unable to represent themselves. Discussion of these moments led to the themes of opportunities and challenges that we discuss in our results. The research team identified moments from several families to illustrate the themes. Each author drafted vignettes that then were discussed as a team and later iterated on until the team agreed on the written vignette.

\section{RESULTS}

While the goals of the program were to introduce families to computational thinking and programming skills, our analysis focused on what and how families were able to represent their stories. Our findings are broadly categorized into moments where (1) interactions with ScratchJr supported their storytelling and may have even brought their stories into new directions, and (2) challenges and limitations that families encountered as they tried to represent their stories. 


\subsection{Opportunities in the tool for storytelling}

Families created a range of projects that included stories about family reunions, trips to spend time together or to visit family in other states, and activities such as birthday parties and going to the park. As families began to represent their stories, families personalized their project using various features in ScratchJr. For example, one family was creating a birthday scene about the youngest child. They were about to write "Feliz Cumpleaños" (Happy Birthday), but after a facilitator's suggestion, they instead recorded themselves saying "Feliz Cumpleaños." In addition, they took a picture of the youngest child's face and imported it into the face of another character. Features like recording sounds, adding their faces to characters, and a library of provided images enabled families to make their project more personal.

For some families, translating their stories provided an opportunity to revisit their stories and experiences more closely. Families had to break down their stories into individual characters, backgrounds, and actions as they translated their stories from oral and paper-based storytelling into the features of ScratchJr. For example, a mother Nina and her two daughters were trying to find a background with a tent for their camping project. Upon seeing a background in the ScratchJr library of images with a cabin, Nina realized that they actually stayed in a cabin.

Nina: Ah, ahí está una casita. Usamos esa? De hecho, nos quedamos en un cabana. Ustedes se llevaron unas casitas de campaña. [Translation: Oh, there is a house there. Should we use that one? We actually did stay in a cabin. You took your little tents.]

As they discussed what else to add, Nina and her daughters learned that they could add emojis. As they scrolled through the flags section, the youngest daughter Lorena saw the Mexican flag and wanted to add it. Afterwards, Nina encouraged Lorena to write her name beside the flag emoji. Having a library of assets that include images and a full range of emojis triggered memories from their stories and inspired new ideas in their projects.

For some families, experimenting and tinkering with the code transformed how they expressed their stories. We share this vignette of Arturo, a young participant who attended the workshop with his mother and older brother Roberto, to describe how tinkering with the computational and digital affordances transformed his family story.

When it came time to develop a story, Roberto and Arturo worked on separate iPads while their mother sat close to them and observed. Arturo decided to create a project about a family trip to visit his aunt, which required a plane ride. When he shared his story with another facilitator, he mentioned that he was scared of airplanes. As he got started with ScratchJr, Arturo experimented with the blue Motion blocks. He connected multiple Move Right blocks together and tapped on them, which made a character move to the right on the screen. Later Arturo and his brother Roberto looked over each other's project. Arturo noticed that Roberto programmed his characters to speak with dialog bubbles and noticed that Roberto added his face to one of his characters. In both instances, Arturo asked his brother for help and Roberto showed him the steps. Arturo changed the default "hi" text to say "I,m scard [I'm scared]" in one of his characters. He also took a picture of his face with his mouth wide open and changed the face of a pilot character to his own. He later added a second pilot and plane and took a picture of his brother's face for the pilot. He continued to play with the movement blocks and added Turn blocks as well as Move $U p$ blocks that made his airplanes move up and down along with making loops in the air. He experimented with the Loop block by wrapping it around his motion blocks and it made these movements repeat over and over again. (See Figure 2) As he made changes in his code, Arturo repeatedly ran his project to see how the planes moved, now with his and his brother's faces on the pilot characters.

As Arturo tinkered with the programming blocks and experimented with motion, he engaged with some key affordances of the computational material: breaking down actions into coding blocks to control and animate objects and characters; experimenting with different commands and playing his program to see what happened; and quickly and repeatedly running his project from the beginning to the end. Arturo experimented with computational features like loops and sequences to create airplane movement that was more playful than moving across the screen. He also experimented with the digital features by adding dialog and his face onto characters, bringing him into his story in a new way. He transformed his story from a fear of being in planes into a story where he was in control, as he programmed the plane movement and made himself the pilot.

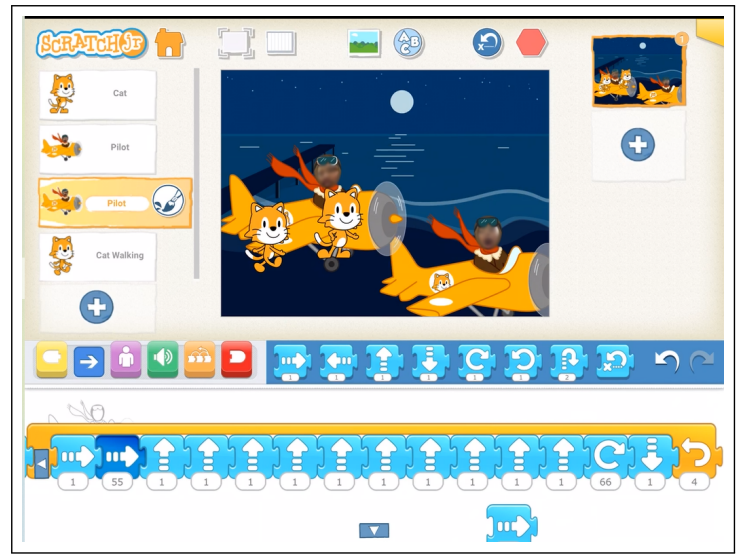

Figure 2: Screenshot of Arturo's project with his and his brother's faces as the pilots. Faces blurred for confidentiality.

While most families had a particular story in mind when they began working with ScratchJr, some families improvised stories as they experimented and tinkered with ScratchJr. To describe this improvisational process, we present this vignette of Jessica and Marcelo, two siblings who attended with their younger sister and mother.

Jessica and Marcelo worked together on one iPad while their sister and mother worked on another. As Jessica and Marcelo explored the image library in ScratchJr, Jessica discovered a girl on a bike with a blank face, reminding her of her bikerides. She then asked a facilitator for help to add her face onto the character. The siblings continued to quietly work together as they added more assets such as a park background and another character on a bike 
for Marcelo. A facilitator Emilia noticed the multiple characters and scenes and suggested programming their characters to move. They then asked Emilia for help to move their bikes from one end of the screen to the other. As Marcelo and Jessica interacted with Emilia, they continued to iteratively ask questions about different movements to build their project. For example, after programming one character to move, Jessica asked how to make characters move at the same time. Emilia then showed Jessica to notice how she needs to program each character. As she continued to help them and they continued to ask questions, Emilia showed them how to make more advanced moves. She showed them how to programmatically change their scenes rather than clicking on each scene in the ScratchJr interface. Later they played with perspective by shrinking a character on a bike to make it seem like the character was moving into the distance.

Facilitators like Emilia in Jessica and Marcelo's experiences supported them to iteratively build up their project and take up the different affordances of ScratchJr. These vignettes highlight the tinkerability design principle of ScratchJr: "the extent to which a user can incrementally learn unfamiliar aspects of the tool and iteratively build up a project" [11]. Families were able to incrementally build their ideas and stories, responding to the materials and features within ScratchJr. Facilitators and family members supported the discovery of unfamiliar features while the immediate feedback of ScratchJr allowed for low-risk experimentation.

\subsection{Challenges and how families responded to them}

In the above section, we described the ways that families were able to leverage ScratchJr to express their stories. However, families also encountered challenges. Some of these challenges were usability issues such as figuring out how to delete or undo actions - challenges that could be improved with future design iterations of ScratchJr. We specifically highlight resistances and limitations within ScratchJr that created friction between their intentions and what they could do with the tool. These experiences with friction ranged from challenges with finding assets to issues of self-representation.

For many challenges, families would experiment and troubleshoot themselves or ask for help from a family member. Sometimes a facilitator might notice and intervene. In these instances, challenges were opportunities for family members to learn more and to deepen their engagement. We share this vignette from a family learning to programmatically start their projects. In the first workshop where parents were introduced to ScratchJr before their children, a father and mother pair Celso and Ana attempted to make a few characters move. However, when they pressed the "Green Flag" button to start their project, their characters did not move. A facilitator Amy noticed their issue and stepped in. She clarified how the Green Flag button is connected to the Green Flag code block. Afterwards, Celso and Ana added the Green Flag code block to the start of each character's code and pressed the Green Flag button. Later Ana and Celso introduced their daughter Camila to ScratchJr. When it was time to add movement, Celso reminded them to add the Green Flag block. When they started their project, Camila became surprised and asked how it was moving. Ana replied, "The [Green] Flag!". In a later workshop, when Camila created her own character and added motion blocks, she reminded herself and her parents about the Green Flag block to start their project.

Not all challenges had clear benefits or learning opportunities. Some encounters with challenges seemed more ambiguous in their outcomes. For example, when trying to look for available assets to represent their families, families sometimes found that the available assets were not comprehensive enough to match their storytelling needs and families had to make compromises to their story vision. Revisiting Nina's family and their story about their annual camping trip, they ran into a few challenges representing elements of their story. First, when scrolling through the provided backgrounds of ScratchJr, they were unable to find an outdoor nighttime scene with a river and instead chose a daytime scene with a river. Afterwards, instead of a campfire, they found an "exploding" sprite with the word "boom" written on it. (The sprite was created by a previous user of the iPad.) They wanted to add someone swimming but, since they could not find a swimmer, they added a fish. (See Figure 3)

In a post-workshop interview, Nina recounted navigating the different sprites and the details of their story.

"[Lorena] said, 'Mom, but it's not night. Fire is at night.' I say, 'But yeah, but we don't have a scenery at night' and we were looking for scenery with fire... And that's okay, we can have it at day too."

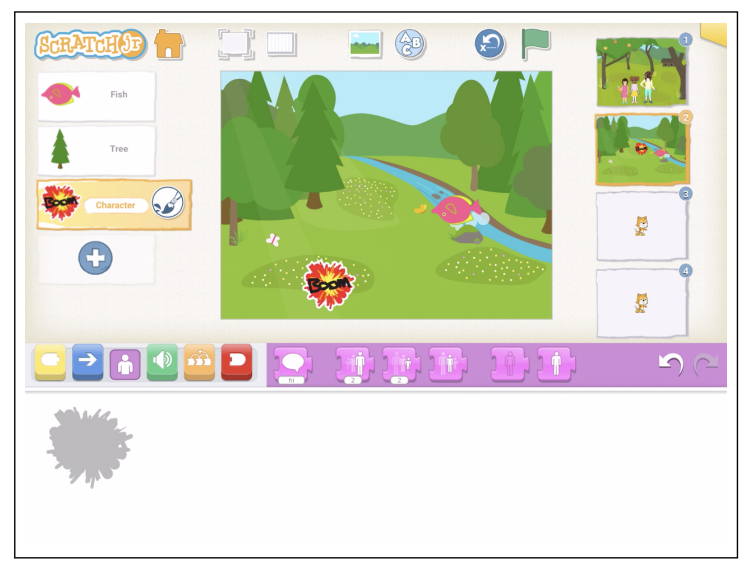

Figure 3: Screenshot of Nina, Lorena, and Maya's ScratchJr project of their camping trip. The "explosion" sprite that they use to substitute their campfire appears on the bottom left of the ScratchJr stage.

When then trying to represent their camping experience in ScratchJr, her children tried to find their story elements in the provided assets. Unfortunately, they were unable to find assets that matched their intended story elements. Nina helped them negotiate the assets of ScratchJr to approximate these story elements.

Many families faced challenges in representing themselves and their stories and became invisibilized along race, language, cultural norms, and other important features to their family. One common challenge was representing their racial and ethnic identities. In another project by brother and sister Marcelo and Jessica, they worked on a story to share a family trip to Disneyland. Marcelo 
tried to represent his youngest sister, but it took a few attempts to find a character to match his sister. At first, he added a young Black girl with pigtails. He later deleted this character for a young White girl with pigtails. Other children seemed to pick characters with lighter skin tones when they had to decide on a character. When brothers Arturo and Roberto were picking characters to represent themselves, they picked the "Father" character who had light brown skin, but the character ended up being too tall when they added it to the scene. Because they could not figure out how to resize it, they deleted the Father character and chose a little blond boy to represent themselves. Another pair of brothers $\mathrm{Cal}$ and Hamid tried to represent their family members in their story. To represent their mother, they used a provided character from the ScratchJr library called "Mother," a White woman with blonde hair in a ponytail wearing blue pants and a pink shirt (see Figure 4). Upon seeing her son's choice, their mother Julia joked about the Mother character and shared that ScratchJr made her look skinny. She brought this up again in a post-workshop interview when we asked her what she thought of ScratchJr. Other children in the workshop used this "Mother" character. However, all mothers, like Cal and Hamid's mother, were Latinx and had darker skin and hair with varying body shapes and styles of dress.

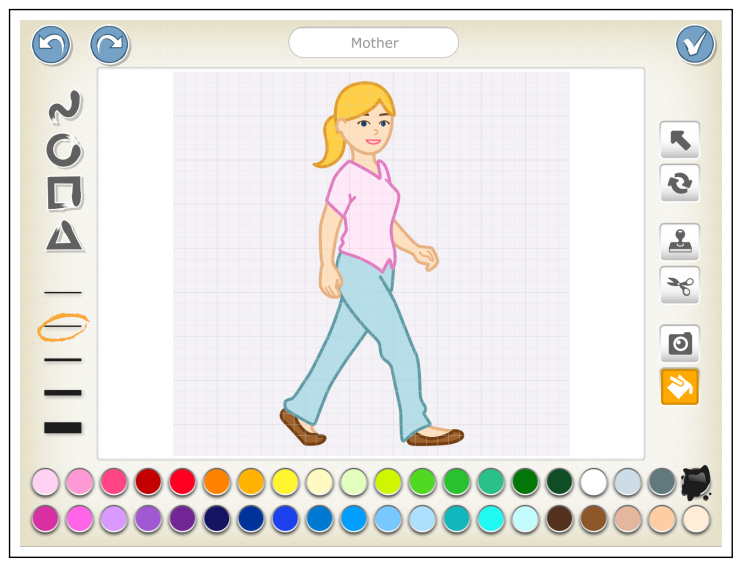

Figure 4: The "Mother" sprite in ScratchJr as seen through the ScratchJr paint editor.

In addition to their bodies, some families struggled to represent the environments in their stories. Mother and daughter pair Ana and Camila created a story about the different places they had lived, which included four settings, three in the United States and one in Mexico. However, when it came time to create their Mexico scene, they repeatedly tried out different backgrounds, but felt unsatisfied with any of their attempts. Eventually Camila concluded that there was no background for Mexico. Ana chose an outdoor park scene to represent their hometown.

Camila: ¡No hay nada de México! [Translation: There is nothing for Mexico!]

Ana: No, este esta bien. [Translation: No, this one is okay.]
Like Nina with her two daughters, Ana also had to facilitate a compromise with key features of their stories. In Ana's and Camila's case, this compromise included their family's place of origin.

Some challenges were not limited to faces, bodies, and environments, but also to language. In Workshop 1, when parents were first introduced to ScratchJr, two mothers Juila and Lucia worked next to each other. After creating characters, they tried to make their characters say "hola" instead of the default "hi." However, after typing in "hola" on their iPads, they clicked out of the textbox instead of clicking "Go" which would have saved their entry. This misstep returned the text back to the default "hi." They repeated these steps a few times (still clicking outside the textbox rather than clicking "Go"). They eventually concluded that Spanish did not work in ScratchJr. Table 1 shares their screenshot and dialog of their attempt to write in "hola."

While ScratchJr does support users to enter whatever text they would like in the textboxes, because of their experiences, Lucia and Julia interpreted that ScratchJr did not support Spanish, their native and primary language. Instead, they initially concluded that they must enter text in English and therefore had to translate their stories into English. Later in the workshop, after other families shared their projects which included Spanish text, Julia and Lucia learned that they could enter Spanish in text. They then asked a facilitator for help.

\section{DISCUSSION}

For many initiatives and programs that aim to incorporate culturally responsive computing to engage groups historically marginalized by computing, computational "construction kits," or systems that allow people to create and build that leverage computer programming, are key tools and technologies. In our study, we focused on the design of a particular computational construction kit, the ScratchJr programming environment, in the context of a program that aimed to engage children and families in culturally responsive ways through using code to represent their family stories. Studying families' interactions with their story and ScratchJr enabled us to examine how families encountered the affordances and limitations and how it impacted their ability to represent their stories. In this section we discuss our findings and implications for the design of computational construction kits and their uses in culturally responsive contexts.

In their paper describing the ideas of culturally responsive computing (CRC), Scott, Sheridan, and Clark highlight a tenet that "the learning context supports transformational use of technologies" that is, learners should be able to use technology to express, explore, and invent [36]. We found that families were able to revisit their stories and, at times, transform their stories in new ways. Families engaged in a generative and improvisational process to represent their stories using the computational and digital affordances of ScratchJr. For example, by experimenting and tinkering with Motion code blocks, Arturo turned a simple plane ride into a playful exploration of movement. Leveraging some of the customization features such as adding his face to a character, Arturo also put himself in control of the plane - positioning himself in an empowered position. This back-and-forth interaction between family members 


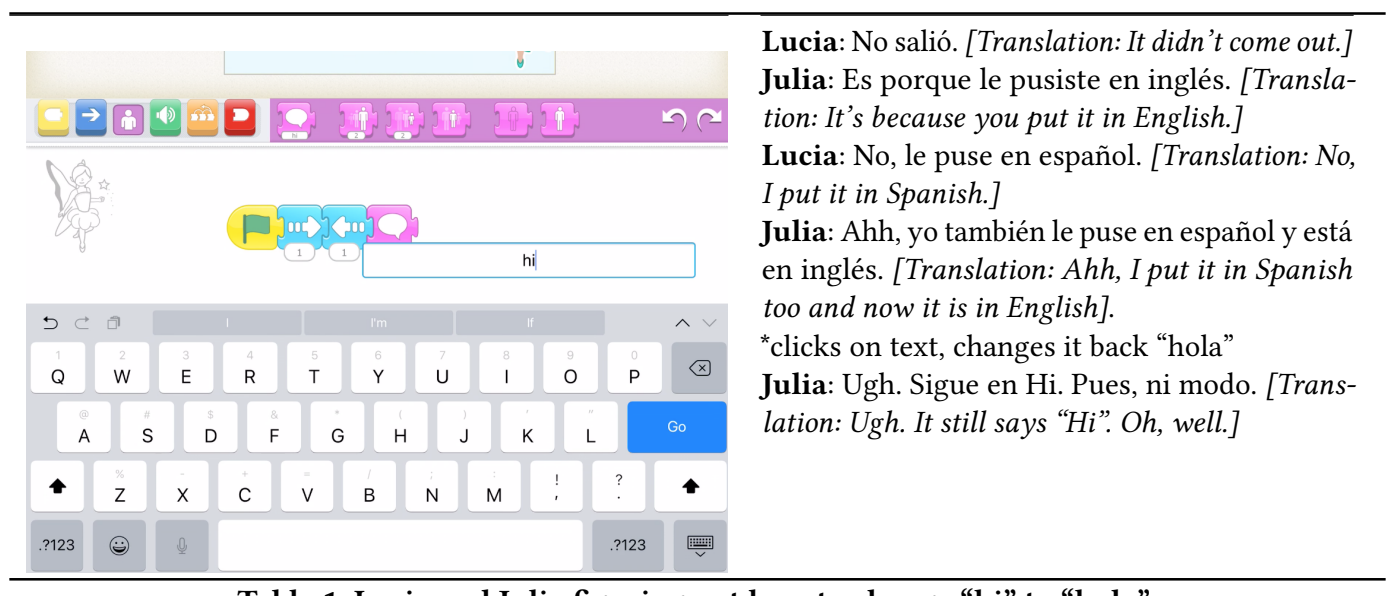

Table 1: Lucia and Julia figuring out how to change "hi" to "hola".

and the tools influenced what stories they made and how these stories were expressed.

Challenges were moments where facilitation from parents and other adult facilitators were necessary. This support from adults and educators echoes the work of other researchers who have highlighted that access to technology alone was not enough to take up the benefits but educators and adult caretakers played important roles $[3,4]$. Program design also mattered. In FCL, the parents were introduced to ScratchJr to then introduce and support their children's engagement with ScratchJr. This arrangement set up parents to play key roles right away. In addition, sharing and hearing from other families and their projects helped families to learn about new ideas and features. However, for some workarounds, the outcomes were more ambiguous. Revisiting Nina and her daughters' their camping project, their family's negotiation and compromise highlighted some of the constraints of expression within ScratchJr. The provided assets limited their imagination of what could be possible in ScratchJr and compromised on important details in their camping experience. Nina had to facilitate making a compromise with her children. While compromises are inevitable in any medium, we find these moments poignant when we situate their participation in context of computing. Families from nondominant groups in computing are trying to represent themselves and their stories using creative computing tools. Ultimately, families needed to make compromises and invisibilize important features of themselves and their own stories. This finding adds onto the work of other researchers studying the embedded biases of creative technologies and how it can invisibilize the identities and participation of nondominant groups in computing [1,20,21].

However, in a program where all participants were Latinx, nearly all families experienced challenges representing themselves and elements of their stories. While provided assets could help get them started or even inspire them, families could not recognize their bodies, their language, their environments, and other important cultural features within the provided image assets of ScratchJr. Even while there were ways to customize their characters, objects, or backgrounds, the provided customization still did not allow them to reflect themselves and their stories. Families could take pictures of their faces and insert it into characters with blank faces, but the bodies did not match theirs. Even though they could switch the default white skin color, the shape of the bodies and the style of the clothes could not be changed. One of the other key ideas from CRC is for youth to be able to explore and express their intersectional identities. Scott, Sheridan, and Clark also argue that CRC contexts should critically reflect and question "who creates, for whom, to what ends rather than who endures socially and culturally irrelevant curriculum." [36]. We can expand this to include that learners should not have to also endure socially and culturally irrelevant user experiences with technologies.

Issues with self-representation could influence their sense of belonging not just in program, but also in computing in general. In an essay arguing for more justice-oriented approaches to CS education, Sepher Vakil emphasizes that "CS learning environments and reform efforts convey messages to students about who they are and who they might become through their participation in the world of computing." [41]). In their study of "identity resources" in learning environments, Nasir and Cooks describe that material resources, which include the physical environment and the artifacts within it, as well as ideational resources, which communicate what is valued, can contribute to the ways in which students develop a sense of connection with an activity [24]. We argue that computational construction kits used in these environments can hold messages to students and families about "who they are and who they might become" and whether they belong in computing contexts.

\subsection{Implications for Designers and Educators}

Reflecting on the implications for designers of technologies and programs, how might we support youth and families from nondominant groups to leverage opportunities, work through challenges, and mitigate these issues of representation with computational construction kits? Within ScratchJr, we believe that some adjustments would help to improve what and how learners can express their stories - and that these adjustments would be applicable to other computational construction kits and creative technologies for children. For example, including a library of images made it easy for families to get started, which connects to an often cited 
principle of having a "low floor" $[11,30]$. However, the design team needs to diversify these assets across characters, settings, objects, and aesthetics. The design team could work with diverse illustrators, especially illustrators from groups that have been historically marginalized in computing spaces. Additionally, families appreciated being able to customize their projects and features like a paint editor enabled families to create their own assets. The design team could also include ways for users to import and edit their own images. Families could then take images of themselves and their neighborhoods or import images from their experiences and incorporate these images directly into their projects.

One of the key principles of ScratchJr is its tinkerability: "Make it easy to incrementally build up creations and knowledge by experimenting with new ideas and features." While Resnick and Silverman hint at supporting many styles of engagement in their set of design principles for construction kits, we want to highlight the important role of designing for tinkerability [30], especially in culturally responsive computing contexts that aim to center youth as innovators capable of transformative uses of technology [36]. Building on arguments from Turkle and Papert for more "epistemological pluralism" in computing spaces [39], Resnick and Rosenbaum argue that designing systems for tinkerability enables and revalues more experimental, playful, and concrete styles of engagement with STEM and computing compared to forms of engagement that prioritize abstract, planning-oriented, and single-solution approaches [30] For computational construction kits, tinkerability must not only be in the code, but also in the user interface of the programming environment. For ScratchJr, this tinkerability manifested in the ways that families could click on individual blocks or sequences of blocks and immediately see what happened to their characters or how families became inspired from the available characters. Families then incrementally built their stories as they experimented and tinkered with the different features of ScratchJr.

Furthermore, we want to highlight the value of working with families, in particular working with families from nondominant groups as part of the design process. To engage children and families in culturally responsive computing contexts, designers and educators need to invite and build on families' rich "funds of knowledge" or the accumulated set of skills, practices, and knowledge that support family well-being [23]. In the FCL workshops, these "funds of knowledge" emerged in the ways that family members helped one another such as when Roberto helped Arturo with ScratchJr features, how parents like Nina facilitated her daughters' interactions with the tools, and in the kinds of stories that families told about their backgrounds, values, and identities. Families were able to leverage and apply their funds of knowledge in FCL - reproducing and building resiliency in their funds of knowledge in the context of computing. In a study interviewing parents that supported their children to take up coding kits, Yu and collaborators argued that programming environments and other related kits need to consider the ways parents support their children in the design of these tools [44]. We expand on this recommendation to emphasize that designers and educators need to consider the whole family and the "funds of knowledge" that youth and their families possess. Designers might engage in a co-design process with families [9, 42, 43], but, as we found in the FCL workshops, it was also valuable to observe families' engagement with technologies in a culturally responsive computing context. For our future work, we plan to examine the ways that families' funds of knowledge emerged and interacted within this CRC context paying closer attention to their development and learning trajectories.

$\mathrm{CRC}$ contexts especially aim to engage people to use computational construction kits or other technologies to create projects that are personally and culturally meaningful to them such as their family stories. Designers and educators should be aware how these tools are creating opportunities and challenges especially for nondominant groups. Features and affordances of these tools might be perceived as neutral by dominant groups, but these features can affect what people make, how they make, and their perceptions of who they are in the context of computing.

\section{SELECTION AND PARTICIPATION OF CHILDREN}

In this study, we recruited 14 children (ages 5 to 10 years old; 7 male, 7 female) in collaboration with their teacher from the English Language Learners Program in their elementary school. Researchers met with their parents in the first FCL workshop to describe the research project and parents reviewed and signed consent forms that described the research, data collection (e.g. observations, photos, interviews), and our process to maintain their confidentiality. We emphasized to parents that data would be kept in a secure location and data would not be shared outside of our research team. We also added that we would use pseudonyms if we referred to their experiences in any external publications. The research study was approved by our Institutional Review Board.

\section{ACKNOWLEDGMENTS}

We would like to thank the families and facilitators that ate, met, made, and shared with us. This project was made possible in part by the Institute of Museum and Library Services LG-96-17-0176-17.

\section{REFERENCES}

[1] Morgan G Ames and Jenna Burrell. 2017. 'Connected Learning'and the Equity Agenda: A Microsociology of Minecraft Play. In Proceedings of the 2017 ACM conference on computer supported cooperative work and social computing. 446-457.

[2] Filiberto Barajas-López and Megan Bang. 2018. Indigenous making and sharing: Claywork in an Indigenous STEAM program. Equity \& Excellence in Education 51, 1 (2018), 7-20.

[3] Brigid Barron, Kimberley Gomez, Nichole Pinkard, and Caitlin K Martin. 2014. The digital youth network: Cultivating digital media citizenship in urban communities. MIT Press.

[4] Brigid Barron, Caitlin Kennedy Martin, Lori Takeuchi, and Rachel Fithian. 2009. Parents as learning partners in the development of technological fluency. (2009).

[5] Karen Brennan and Mitchel Resnick. 2012. New frameworks for studying and assessing the development of computational thinking. In Proceedings of the 2012 annual meeting of the American educational research association, Vancouver, Canada, Vol. 1. 25.

[6] Leah Buechley, Mike Eisenberg, Jaime Catchen, and Ali Crockett. 2008. The LilyPad Arduino: using computational textiles to investigate engagement, aesthetics, and diversity in computer science education. In Proceedings of the SIGCHI conference on Human factors in computing systems. 423-432.

[7] Leah Buechley, Kylie Peppler, Michael Eisenberg, and Kafai Yasmin. 2013. Textile Messages: Dispatches from the World of E-Textiles and Education. New Literacies and Digital Epistemologies. Volume 62. ERIC.

[8] Beginner's Mind Collective and David Shaw. 2012. Makey Makey: Improvising Tangible and Nature-Based User Interfaces. In Proceedings of the Sixth International Conference on Tangible, Embedded and Embodied Interaction (Kingston, Ontario, Canada) (TEI '12). Association for Computing Machinery, New York, NY, USA, 367-370. https://doi.org/10.1145/2148131.2148219 
[9] Betsy DiSalvo, Jason Yip, Elizabeth Bonsignore, and Carl DiSalvo. 2017. Par ticipatory design for learning: Perspectives from practice and research. Taylor \& Francis.

[10] Ron Eglash, Juan E Gilbert, and Ellen Foster. 2013. Toward culturally responsive computing education. Commun. ACM 56, 7 (2013), 33-36.

[11] Louise P. Flannery, Brian Silverman, Elizabeth R. Kazakoff, Marina Umaschi Bers, Paula Bontá, and Mitchel Resnick. 2013. Designing ScratchJr. Proceedings of the 12th International Conference on Interaction Design and Children - IDC 13 (2013). https://doi.org/10.1145/2485760.2485785

[12] Scratch Foundation. 2020. Cultivating a World of Creativity: 2019 Annual Report Scratch Fdn, Boston, MA.

[13] George Franz and Seymour Papert. 1988. Computer as Material: Messing about with Time. Teachers College Record 89, 3 (1988), 408-17.

[14] Norma González. 2005. Beyond culture: The hybridity of funds of knowledge. Funds of knowledge: Theorizing practices in households, communities, and classrooms (2005), 29-46.

[15] Kris D Gutiérrez, P Zitlali Morales, and Danny C Martinez. 2009. Re-mediating literacy: Culture, difference, and learning for students from nondominant communities. Review of research in education 33, 1 (2009), 212-245.

[16] Tim Ingold. 2010. The textility of making. Cambridge fournal of Economics 34, 1 (2010), 91-102.

[17] Yasmin Kafai, Kristin Searle, Crîstobal Martinez, and Bryan Brayboy. 2014. Ethnocomputing with Electronic Textiles: Culturally Responsive Open Design to Broaden Participation in Computing in American Indian Youth and Communities (SIGCSE '14). Association for Computing Machinery, New York, NY, USA, 241-246. https://doi.org/10.1145/2538862.2538903

[18] Jody Koenig Kellas and April R Trees. 2006. Finding meaning in difficult family experiences: Sense-making and interaction processes during joint family storytelling. The fournal of Family Communication 6, 1 (2006), 49-76.

[19] Jean Lave, Etienne Wenger, et al. 1991. Situated learning: Legitimate peripheral participation. Cambridge university press.

[20] Breanne K Litts, Kristin Searle, Megan Hamilton, Kameica Yazzie, and Cedric Mannie. 2020. Diversifying Computational Tools: How Technology Affords and Constrains Indigenous Youths' Design Agency. (2020).

[21] Breanne K Litts, Kristin A Searle, Bryan MJ Brayboy, and Yasmin B Kafai. [n.d.] Computing for all?: Examining critical biases in computational tools for learning. British fournal of Educational Technology ([n. d.]), e13059.

[22] Jane Margolis, Jean J Ryoo, Cueponcaxochitl DM Sandoval, Clifford Lee, Joanna Goode, and Gail Chapman. 2012. Beyond access: Broadening participation in high school computer science. ACM Inroads 3, 4 (2012), 72-78.

[23] Luis C. Moll, Cathy Amanti, Deborah Neff, and Norma Gonzalez. 1992. Funds of knowledge for teaching: Using a qualitative approach to connect homes and classrooms. Theory Into Practice 31, 2 (1992), 132-141. https://doi.org/10.1080/ 00405849209543534

[24] Na'ilah Suad Nasir and Jamal Cooks. 2009. Becoming a hurdler: How learning settings afford identities. Anthropology \& Education Quarterly 40, 1 (2009), 41-61.

[25] Na'ilah Suad Nasir and Victoria M Hand. 2006. Exploring sociocultural perspectives on race, culture, and learning. Review of educational research 76, 4 (2006), 449-475.

[26] Anna Newley, Hasan Deniz, Erdogan Kaya, and Ezgi Yesilyurt. 2016. Engaging elementary and middle school students in robotics through hummingbird kit with Snap! visual programming language. Fournal of Learning and Teaching in Digital Age 1, 2 (2016), 20-26.

[27] Seymour Papert. 1990. Children, computers and powerful ideas.

[28] Nichole Pinkard, Sheena Erete, Caitlin K. Martin, and Maxine McKinney de Royston. 2017. Digital Youth Divas: Exploring Narrative-Driven Curriculum to Spark Middle School Girls' Interest in Computational Activities. Journal of the
Learning Sciences 26, 3 (2017), 477-516. https://doi.org/10.1080/10508406.2017. 1307199 arXiv:https://doi.org/10.1080/10508406.2017.1307199

[29] Mitchel Resnick, John Maloney, Andrés Monroy-Hernández, Natalie Rusk, Evelyn Eastmond, Karen Brennan, Amon Millner, Eric Rosenbaum, Jay Silver, Brian Silverman, and Yasmin Kafai. 2009. Scratch: Programming for All. Commun. ACM 52, 11 (Nov. 2009), 60-67. https://doi.org/10.1145/1592761.1592779

[30] Mitchel Resnick and Eric Rosenbaum. 2013. Designing for tinkerability. Design, make, play: Growing the next generation of STEM innovators (2013), 163-181.

[31] Mitchel Resnick and Brian Silverman. 2005. Some reflections on designing construction kits for kids. Proceeding of the 2005 conference on Interaction design and children - IDC 05 (2005). https://doi.org/10.1145/1109540.1109556

[32] Ricarose Roque. 2016. Family Creative Learning. In Makeology: Makerspaces as learning environments, Kylie Peppler, Erica Halverson, and Yasmin B Kafai (Eds.). Vol. 1. Routledge New York, NY, 47-63.

[33] Ricarose Roque and Rupal Jain. 2018. Becoming Facilitators of Creative Computing in Out-of-School Settings. International Society of the Learning Sciences, Inc.[ISLS].

[34] Ricarose Roque and Kristina Stamatis. 2020. It's about relationships: Examining facilitation as a relational practice. Proceedings of the 2019 Connected Learning Summit (2020), 155-163.

[35] Jean Ryoo, Joanna Goode, and Jane Margolis. 2015. It takes a village: Supporting inquiry-and equity-oriented computer science pedagogy through a professional learning community. Computer Science Education 25, 4 (2015), 351-370.

[36] Kimberly A Scott, Kimberly M Sheridan, and Kevin Clark. 2015. Culturally responsive computing: A theory revisited. Learning, Media and Technology 40, 4 (2015), 412-436.

[37] Sue Sentance, Jane Waite, Steve Hodges, Emily MacLeod, and Lucy Yeomans. 2017. " Creating Cool Stuff" Pupils' Experience of the BBC micro: bit. In Proceedings of the 2017 ACM SIGCSE technical symposium on computer science education. 531-536.

[38] Mia Shaw and Yasmin Kafai. 2020. Charting the Identity Turn in K-12 Computer Science Education: Developing More Inclusive Learning Pathways for Identities. (2020).

[39] Sherry Turkle and Seymour Papert. 1992. Epistemological pluralism and the revaluation of the concrete. Fournal of Mathematical Behavior 11, 1 (1992), 3-33.

[40] Carrie Tzou, Meixi, Enrique Suárez, Philip Bell, Don LaBonte, Elizabeth Starks, and Megan Bang. 2019. Storywork in STEM-Art: Making, Materiality and Robotics within Everyday Acts of Indigenous Presence and Resurgence. Cognition and Instruction 37, 3 (2019), 306-326. https://doi.org/10.1080/07370008.2019.1624547 arXiv:https://doi.org/10.1080/07370008.2019.1624547

[41] Sepehr Vakil. 2018. Ethics, identity, and political vision: Toward a justice-centered approach to equity in computer science education. Harvard Educational Review 88, 1 (2018), 26-52.

[42] Jason C Yip, Tamara Clegg, June Ahn, Judith Odili Uchidiuno, Elizabeth Bonsignore, Austin Beck, Daniel Pauw, and Kelly Mills. 2016. The evolution of engagements and social bonds during child-parent co-design. In Proceedings of the 2016 CHI Conference on Human Factors in Computing Systems. 3607-3619.

[43] Jason C Yip, Kiley Sobel, Caroline Pitt, Kung Jin Lee, Sijin Chen, Kari Nasu, and Laura R Pina. 2017. Examining adult-child interactions in intergenerational participatory design. In Proceedings of the 2017 CHI Conference on Human Factors in Computing Systems. 5742-5754.

[44] Junnan Yu, Chenke Bai, and Ricarose Roque. 2020. Considering Parents in Coding Kit Design: Understanding Parents' Perspectives and Roles. In Proceedings of the 2020 CHI Conference on Human Factors in Computing Systems. 1-14.

[45] Junnan Yu and Ricarose Roque. 2018. A survey of computational kits for young children. Proceedings of the 17th ACM Conference on Interaction Design and Children (2018). https://doi.org/10.1145/3202185.3202738 